\title{
Field Screening of Cassava (Manihot esculenta Crantz) Germplasm for Desirable Traits by the Use of Augmented Design
}

\author{
I. K. Asante ${ }^{1 *}$ and A. G. O. Dixon ${ }^{2}$ \\ ${ }^{1}$ Department of Botany, University of Ghana, P. O. Box LG55, Legon, Ghana \\ ${ }^{2}$ International Institute of Tropical Agriculture, Ibadan, Nigeria \\ *Corresponding author; Email: ikasante@yahoo.com
}

\begin{abstract}
Ninety-eight cassava accessions were grown in augmented randomized complete block design to screen for superior clones with desirable traits. The desirable traits were root number (RTNO), fresh root yield (FYLD), harvest index (HI), dry matter (DM), cyanide potential (CNP), mean plant height (MPHT) and level of branching (LOBR). Three standard varieties were used, namely $30572,91 / 01730$ and $91 / 023227$. Acessions that were superior to the standard types in more than one trait were 92/0681, 92/02325; 92/0455, 88/02555; Alice Local and 88/02555. These accessions could be selected and put into crossing blocks to combine the traits into one genotype. The present results show that augmented designs are efficient in the identification of superior cassava genotypes with desirable traits.
\end{abstract}

\section{Introduction}

Cassava originates from Latin America and it was initially introduced to Africa 400 years ago from where its cultivation for food spread through the tropical and subtropical regions (Marmey et al., 1994). The crop is one of the major sources of food in Africa. It is fourth after rice, sugar cane and maize as a source of calories in human diet, feeding more than 500 million people in Africa, Asia, and Latin America (Roa et al., 1997). Targets for cassava breeding in Africa include high-yielding low cyanogenic glucosides, early bulking, pest and disease tolerance.

Selection for desirable traits is necessary to enhance cassava breeding in Africa. The initial stages of breeding programmes include field-testing of large numbers of accessions. The tests are laborious, time consuming and need to be repeated to minimize effects of uncontrolled environmental factors. With limited resources, the breeder needs to increase efficiency at an early testing in order to reduce the number of clones for uniform trials. Federer (1961), working with sugar cane, proposed the augmented designs as a solution to overcome the problem of having large number of genotypes for field-testing. These designs allow elimination of soil differences as common causes of error in comparison of entries, and can successfully be employed in genetic studies and breeding programmes for crop improvement, being more cost effective than fully replicated trials (Spehar, 1994). These designs are derived from expanded randomized complete blocks in which standard varieties are present in all blocks. The empty spaces of the expanded blocks are filled with the varieties for which information about the performance is needed. The statistical analysis on the standard varieties identifies the varying soil attributes as measured by the blocks, and allows one to correct for these and make a valid comparison. The method has been used in field screening trial of soya bean (Spehar, 1994).

The objective of the experiment was to adapt the augmented randomized complete block design to screen cassava germplasm and select superior clones with desirable agronomic traits to facilitate their use in breeding programmes. 


\section{Materials and methods}

Plant materials and experimental design

Ninety-eight early bulking cassava accessions selected from farmers were grown in an augmented randomized complete block design. The experimental design consisted of 11 randomized blocks in each of which three standard cassava genotypes and nine entries were grown, the standard genotypes serving as checks. These standard genotypes, namely 30572, 91/01730 and 91/023227 represented clones with wide range of agronomic characters and were chosen because they were among the standard clones commonly used in the IITA cassava breeding programme.

The trial was carried out at Ibadan in the humid forest agroecological zone of Nigeria. The three genotypes were grown in each block, but each entry to be evaluated was planted only once in the experiment. The positions of the three standard genotypes and the nine entries in each block were fully randomized and planted in rows. Rows were $1 \mathrm{~m}$ apart and each row was $10 \mathrm{~m}$ long. Genotypes were grown under rainfed conditions. Harvesting was done 6 months after planting. At harvesting, the following data were collected: root number (RTNO), fresh root yield (FYLD), harvest index $(\mathrm{HI})$, percent dry matter $(\mathrm{DM})$, cyanide potential (CNP), mean plant height (MPHT) and level of branching (LOBR).

\section{Data analysis}

The observations on the standard genotypes were first subjected to a simple analysis of variance using a randomized complete block design by the SAS PROC MIXED method (Scott \& Milliken, 1993; Wolfinger et al., 1997). This provided information for further analysis with the entries. This analysis takes into account variability amongst blocks, measured by the standard genotypes, according to which the values of entries are adjusted for comparison. The following comparisons were made, using the appropriate standard errors of the difference between means, comparisons between entries in different blocks and comparisons between an entry and a standard genotype. In summary:

(i) Standard error for comparing lines in the same block was: $s \sqrt{ } 2$,

(ii) Standard error for comparing lines between blocks was $\sqrt{ }\left[2\left(\mathrm{~s}^{2}+\mathrm{s}_{\mathrm{b}}{ }^{2}\right)\right]$, where $\mathrm{s}_{\mathrm{b}}{ }^{2}=$ variance between blocks $=($ BLOCK MS - ERROR MS $) /$ number of check lines and $s=\sqrt{ }$ MSE

\section{Results and discussion}

The results of the analysis of variance for the agronomic characters of the three standard genotypes are shown in Table 1. The F-value for genotypes provides a test of the hypothesis that the standard genotype means and the means of the unreplicated clones are equal. The F-value for clone (genotypes) provides a test of the hypothesis that all the means of the unreplicated clones are equal. From this information the means of the standard genotypes differed significantly from those of the unreplicated clones for each of the characters: root number, fresh root yield, harvest index, mean plant height and level of branching; there were no significant differences for dry matter and cyanide potential levels. Block effect was significant for root number, fresh root yield, harvest index and mean plant height among the standard genotypes.

TABLE 1

Analysis of variance for standard genotypes used in the augmented blocks to adjust the observations for the individual entries 


\begin{tabular}{|c|c|c|c|c|c|c|c|c|c|}
\hline & $D F$ & RTNO & \multicolumn{3}{|c|}{$F Y L D$} & $H I$ & \multicolumn{3}{|c|}{$D M$} \\
\hline Source of variation & & $M S$ & $p$ & $M S$ & $p$ & $M S$ & $p$ & $M S$ & $p$ \\
\hline Block & 10 & 403.82 & 0.013 & 214.2 & 0.006 & 0.012 & 0.029 & 36.29 & 0.512 \\
\hline Genotypes & 2 & 1575.64 & $<0.0001$ & 465.0 & $<0.001$ & 0.077 & $<0.001$ & 96.68 & 0.088 \\
\hline Clone(genotype) & 97 & 126.5 & 0.531 & 52.79 & 0.619 & 0.010 & 0.017 & 15.87 & 0.997 \\
\hline Error & 20 & 127.43 & & 57.10 & & 0.004 & & 38.14 & \\
\hline
\end{tabular}

TABLE 1 cont

\begin{tabular}{lrcrrrrr}
\multicolumn{1}{l}{} & $D F$ & $C N P$ & & $M P H T$ & \multicolumn{3}{c}{ LOBR } \\
Source of variation & & $M S$ & $p$ & $M S$ & $P$ & $M S$ & $p$ \\
& & & & & & & \\
Block & 10 & 227.71 & 0.298 & 998.14 & 0.025 & 0.309 & 0.565 \\
Genotypes & 2 & 20.20 & 0.948 & 2732.39 & $<0.001$ & 4.194 & $<0.0001$ \\
Clone(genotype) & 97 & 66.56 & 0.997 & 596.90 & 0.099 & 0.471 & 0.229 \\
Error 20 & 170.06 & 360.89 & & 0.350 & & &
\end{tabular}

In comparison of the means (Table 2) among the standard genotypes, differences were recorded for root number, fresh root yield, harvest index, mean plant height and level of branching. Genotypes 30575 and 91/023227 performed better than 91/01730 with reference to root number and dry matter. Genotypes $91 / 01730$ and $91 / 023227$ performed better than 30572 in terms of fresh root yield; genotypes 30572 and 91/01730 performed better than 91/023227 in terms of mean plant height. Genotype 30572 performed better than the other two in terms of level of branching.

TABLE 2

Mean performance of the standard genotypes used in the augmented block experiment

$\begin{array}{lrrrrrrr}\text { Genotypes } & \text { RTNO } & F Y L D & H I & \text { DM } & \text { CNP } & \text { MPHT } & \text { LOBR } \\ 30572 & & & & & & & \\ 91 / 01730 & 41.3 & 11.7 & 0.31 & 34.2 & 15.6 & 149.8 & 2.3 \\ 91 / 023227 & 23.5 & 15.4 & 0.45 & 27.4 & 19.7 & 130.8 & 0.8 \\ \text { SED } & 46.4 & 27.0 & 0.58 & 33.4 & 16.4 & 100.6 & 0.7 \\ & 4.8 & 3.2 & 0.03 & 2.6 & 5.6 & 8.1 & 0.3\end{array}$

To compare the entries, adjusted values were obtained using the block effect estimated from the standard genotypes. There were two standard errors to compare the differences of adjusted means: one to compare entries in the same block (ESB); another to compare entries not in the same block (ESNB). These allow all possible comparisons to be made to select the entries for further breeding. The standard errors of the adjusted means are presented in Table 3. It is observed that there are superior clones for the characters under study. Clones that were superior to the standard genotypes were identified for all the agronomic traits within blocks (Table 4). Clones 91/00436, 91/02312, 92/02325, 92/0174, 92/0455 and 92/0681 were superior in terms of root number.

TABLE 3

Standard errors of difference of means to compare cassava clones in the same block (ESB) and those not in the same block (ENSB). 


$\begin{array}{lrr}\text { Character } & \text { ESB } & \text { ENSB } \\ \text { Root number } & 15.96 & 20.96 \\ \text { Fresh yield }(\mathrm{t} / \mathrm{h}) & 10.7 & 14.8 \\ \text { Harvest index } & 0.089 & 0.115 \\ \text { Dry matter } & 8.73 & 8.66 \\ \text { Cyanide potential } & 18.44 & 19.46 \\ \text { Mean plant height }(\mathrm{cm}) & 26.87 & 33.86 \\ \text { Level of branching } & 0.837 & 0.820\end{array}$

TABLE 4

Adjusted values for agronomic characters $(R T N O=$ number of roots; $F Y L D(t / h)=$ fresh root yield; HI $=$ harvest index; DM (\%) = dry matter; CNP $(\mathrm{mg} \mathrm{HCN} / \mathrm{kg})=$ cyanide potential; $M P H T(\mathrm{~cm})=$ mean plant height; LOBR =level of branching) of cassava clones from augmented design

\begin{tabular}{|c|c|c|c|c|c|c|c|c|}
\hline Clones & Block & $R T N O$ & $F Y L D$ & $H I$ & $D M$ & $C N P$ & MPHT & $L O B R$ \\
\hline 2nd Agric & 1 & 18 & 13.3 & 0.43 & 36.5 & 7.6 & 113.4 & 1.5 \\
\hline $4(2) 1425$ & 1 & 34 & 19.2 & 0.47 & 33.2 & 35.0 & 114.3 & 2.2 \\
\hline 30555 & 1 & 24 & 11.7 & 0.31 & 32.8 & 13.8 & 149.8 & 2.3 \\
\hline 63397 & 1 & 22 & 18.1 & 0.52 & 33.3 & 11.7 & 122.5 & 1.6 \\
\hline $86 / 1$ & 1 & 31 & 14.3 & 0.50 & 33.9 & 15.9 & 118.2 & 1.3 \\
\hline $88 / 02555$ & 1 & 42 & 32.5 & 0.53 & 29.2 & 15.1 & 158.0 & 0.6 \\
\hline $90 / 00099$ & 1 & 22 & 12.7 & 0.36 & 35.1 & 21.7 & 152.1 & 1.5 \\
\hline $90 / 00330$ & 1 & 19 & 12.4 & 0.41 & 33.5 & 18.7 & 129.9 & 1.0 \\
\hline $90 / 01058$ & 1 & 25 & 14.7 & 0.53 & 25.0 & 17.9 & 120.1 & 1.3 \\
\hline $90 / 01204$ & 2 & 30 & 11.2 & 0.50 & 35.8 & 21.8 & 88.0 & 2.0 \\
\hline $90 / 01554$ & 2 & 42 & 26.7 & 0.54 & 33.6 & 22.2 & 140.3 & 2.3 \\
\hline $90 / 01718$ & 2 & 28 & 16.4 & 0.44 & 31.7 & 4.1 & 130.1 & 1.9 \\
\hline $91 / 00397$ & 2 & 33 & 15.6 & 0.48 & 29.8 & 13.4 & 169.0 & 1.6 \\
\hline $91 / 00417$ & 2 & 28 & 16.2 & 0.43 & 31.0 & 20.9 & 152.0 & 2.4 \\
\hline $91 / 00419$ & 2 & 35 & 17.4 & 0.47 & 33.5 & 18.4 & 132.8 & 1.2 \\
\hline $91 / 00420$ & 2 & 30 & 15.4 & 0.53 & 30.2 & 3.3 & 101.4 & 1.8 \\
\hline $91 / 00429$ & 2 & 31 & 15.7 & 0.43 & 31.9 & 11.0 & 117.2 & 1.7 \\
\hline $91 / 00436$ & 2 & 51 & 26.0 & 0.49 & 32.1 & 19.6 & 138.5 & 2.0 \\
\hline $91 / 00451$ & 3 & 43 & 21.0 & 0.52 & 38.7 & 20.0 & 121.7 & 2.9 \\
\hline $91 / 00453$ & 3 & 37 & 25.8 & 0.71 & 25.9 & 35.5 & 107.7 & 1.3 \\
\hline $91 / 00454$ & 3 & 27 & 12.1 & 0.36 & 31.4 & 17.9 & 122.7 & 2.4 \\
\hline $91 / 00455$ & 3 & 36 & 19.7 & 0.53 & 28.8 & 13.5 & 100.0 & 2.2 \\
\hline $91 / 00457$ & 3 & 22 & 7.3 & 0.30 & 39.6 & 19.8 & 111.1 & 2.4 \\
\hline $91 / 00458$ & 3 & 30 & 15.7 & 0.45 & 34.4 & 9.8 & 135.2 & 0.7 \\
\hline $91 / 00459$ & 3 & 29 & 16.5 & 0.46 & 31.6 & 21.2 & 118.8 & 2.0 \\
\hline 9100795 & 3 & 28 & 15.5 & 0.33 & 27.5 & 9.4 & 152.8 & 1.8 \\
\hline $91 / 01411$ & 3 & 11 & 6.5 & 0.29 & 39.0 & 18.5 & 122.8 & 2.0 \\
\hline $91 / 01899$ & 4 & 41 & 17.7 & 0.45 & 34.2 & 23.0 & 120.3 & 2.2 \\
\hline 91/01921 & 4 & 15 & 8.0 & 0.25 & 34.0 & 33.3 & 135.9 & 3.1 \\
\hline $91 / 01964$ & 4 & 17 & 5.6 & 0.30 & 33.3 & 21.8 & 158.7 & 0.0 \\
\hline 91/01986 & 4 & 12 & 5.9 & 0.28 & 30.0 & 21.3 & 165.4 & 1.3 \\
\hline $91 / 02214$ & 4 & 15 & 4.9 & 0.15 & 38.8 & 23.6 & 190.2 & 2.4 \\
\hline $91 / 02226$ & 4 & 26 & 13.6 & 0.41 & 36.8 & 9.4 & 165.1 & 1.7 \\
\hline $91 / 02233$ & 4 & 33 & 14.7 & 0.37 & 33.8 & 8.5 & 152.8 & 1.6 \\
\hline $91 / 02312$ & 4 & 49 & 30.8 & 0.53 & 33.7 & 12.5 & 151.0 & 1.4 \\
\hline $91 / 02316$ & 4 & 37 & 18.9 & 0.45 & 35.8 & 16.5 & 117.0 & 1.6 \\
\hline $91 / 02317$ & 5 & 27 & 11.3 & 0.32 & 35.2 & 30.1 & 122.7 & 1.6 \\
\hline $91 / 02319$ & 5 & 24 & 15.2 & 0.40 & 34.9 & 19.8 & 132.8 & 1.8 \\
\hline $91 / 02322$ & 5 & 29 & 17.5 & 0.30 & 31.5 & 7.8 & 141.4 & 2.0 \\
\hline
\end{tabular}




\begin{tabular}{|c|c|c|c|c|c|c|c|c|}
\hline $91 / 02324$ & 5 & 38 & 23.8 & 0.59 & 35.7 & 24.4 & 107.4 & 1.5 \\
\hline $92 / 02325$ & 5 & 55 & 29.2 & 0.61 & 36.4 & 5.7 & 100.8 & 0.3 \\
\hline $92 / 0019$ & 5 & 22 & 9.9 & 0.37 & 33.6 & 22.8 & 112.7 & 1.7 \\
\hline $92 / 0033$ & 5 & 28 & 9.9 & 0.32 & 35.4 & 36.0 & 172.4 & 1.8 \\
\hline $92 / 0038$ & 5 & 32 & 10.7 & 0.29 & 30.8 & 25.8 & 147.0 & 1.8 \\
\hline $92 / 0042$ & 5 & 36 & 19.2 & 0.53 & 34.5 & 24.7 & 141.4 & 2.0 \\
\hline $92 / 0053$ & 6 & 31 & 22.7 & 0.57 & 32.4 & 33.0 & 121.8 & 2.3 \\
\hline $92 / 0057$ & 6 & 29 & 17.4 & 0.31 & 30.4 & 19.9 & 165.2 & 2.3 \\
\hline $92 / 0067$ & 6 & 18 & 12.8 & 0.43 & 41.0 & 8.4 & 109.9 & 0.3 \\
\hline $92 / 0084$ & 6 & 24 & 11.8 & 0.42 & 31.3 & 15.4 & 95.5 & 1.0 \\
\hline $92 / 0099$ & 6 & 37 & 17.2 & 0.44 & 36.4 & 21.0 & 149.0 & 0.7 \\
\hline $92 / 0110$ & 6 & 36 & 17.8 & 0.51 & 25.2 & 19.0 & 123.8 & 1.8 \\
\hline $92 / 0174$ & 6 & 56 & 25.8 & 0.55 & 33.3 & 15.3 & 163.3 & 1.2 \\
\hline $92 / 0287$ & 6 & 32 & 18.3 & 0.42 & 32.2 & 16.9 & 142.4 & 2.2 \\
\hline $92 / 0325$ & 6 & 17 & 7.7 & 0.23 & 21.9 & 20.2 & 131.8 & 2.0 \\
\hline $92 / 0326$ & 7 & 27 & 14.5 & 0.35 & 33.8 & 11.8 & 133.7 & 1.4 \\
\hline $91 / 0342$ & 7 & 45 & 26.1 & 0.55 & 26.8 & 7.1 & 115.8 & 1.0 \\
\hline $92 / 0352$ & 7 & 36 & 18.6 & 0.52 & 31.4 & 9.7 & 117.5 & 0.3 \\
\hline $92 / 0391$ & 7 & 27 & 14.7 & 0.53 & 32.8 & 16.7 & 99.7 & 2.0 \\
\hline $92 / 0396$ & 7 & 11 & 4.6 & 0.19 & 28.6 & 11.7 & 101.6 & 2.1 \\
\hline $92 / 0397$ & 7 & 35 & 20.2 & 0.51 & 35.0 & 13.8 & 116.6 & 1.3 \\
\hline $92 / 0398$ & 7 & 12 & 9.6 & 0.33 & 30.6 & 20.1 & 96.1 & 2.1 \\
\hline $92 / 0401$ & 7 & 30 & 23.7 & 0.47 & 26.3 & 7.9 & 111.3 & 1.0 \\
\hline $92 / 0402$ & 7 & 28 & 14.2 & 0.51 & 33.8 & 25.4 & 84.4 & 1.0 \\
\hline $92 / 0403$ & 8 & 31 & 14.1 & 0.45 & 30.7 & 17.9 & 112.8 & 1.0 \\
\hline $92 / 0427$ & 8 & 32 & 20.4 & 0.46 & 29.5 & 17.2 & 152.5 & 3.2 \\
\hline $92 / 0429$ & 8 & 28 & 17.0 & 0.53 & 27.2 & 8.3 & 82.3 & 0.7 \\
\hline $92 / 0430$ & 8 & 23 & 12.8 & 0.31 & 32.2 & 6.8 & 143.3 & 2.1 \\
\hline $92 / 0455$ & 8 & 56 & 22.0 & 0.49 & 36.3 & 23.1 & 208.3 & 1.6 \\
\hline $92 / 0466$ & 8 & 36 & 14.3 & 0.52 & 33.9 & 6.04 & 95.9 & 0.7 \\
\hline $92 / 0496$ & 8 & 31 & 19.0 & 0.49 & 35.9 & 9.6 & 125.7 & 2.5 \\
\hline $92 / 0509$ & 8 & 45 & 24.3 & 0.60 & 36.3 & 7.7 & 97.6 & 1.9 \\
\hline $92 / 0520$ & 8 & 37 & 21.7 & 0.59 & 35.6 & 8.0 & 123.1 & 0.0 \\
\hline $92 / 0536$ & 9 & 42 & 22.0 & 0.54 & 37.0 & 20.8 & 105.8 & 1.2 \\
\hline $92 / 0600$ & 9 & 24 & 14.3 & 0.44 & 31.6 & 13.7 & 128.7 & 2.0 \\
\hline $92 / 0602$ & 9 & 21 & 14.4 & 0.35 & 32.6 & 9.4 & 157.1 & 2.7 \\
\hline $96 / 0616$ & 9 & 21 & 11.2 & 0.36 & 33.6 & 19.0 & 170.5 & 2.4 \\
\hline $92 / 0681$ & 9 & 51 & 23.7 & 0.46 & 34.0 & 19.9 & 164.1 & 1.6 \\
\hline $92 / 0723$ & 9 & 19 & 10.2 & 0.35 & 32.2 & 25.3 & 157.7 & 2.5 \\
\hline $92 / 0755$ & 9 & 27 & 23.1 & 0.51 & 32.2 & 3.8 & 107.2 & 1.8 \\
\hline $92 / 0987$ & 9 & 27 & 14.2 & 0.47 & 32.3 & 8.8 & 111.1 & 1.8 \\
\hline ALICE LOCAL & 9 & 34 & 32.8 & 0.59 & 22.0 & 25.9 & 148.1 & 2.1 \\
\hline ATU & 10 & 19 & 12.9 & 0.38 & 30.8 & 17.6 & 120.9 & 0.7 \\
\hline BAGI-WAWA & 10 & 27 & 12.5 & 0.38 & 31.1 & 13.3 & 114.5 & 0.7 \\
\hline CB5-10(80411) & 10 & 22 & 15.1 & 0.47 & 39.4 & 13.2 & 114.0 & 1.2 \\
\hline ILORIN-ROGOR & 10 & 19 & 16.5 & 0.49 & 26.7 & 13.8 & 109.9 & 1.7 \\
\hline ISU & 10 & 22 & 14.0 & 0.41 & 35.2 & 29.8 & 138.3 & 1.1 \\
\hline LAPAI-1 & 10 & 26 & 10.1 & 0.39 & 37.4 & 6.7 & 169.0 & 1.6 \\
\hline M85/00665 & 10 & 33 & 21.0 & 0.40 & 35.9 & 6.4 & 129.4 & 1.0 \\
\hline MS-11 & 10 & 44 & 20.3 & 0.51 & 33.8 & 23.4 & 114.7 & 2.2 \\
\hline MS-20 & 10 & 28 & 18.4 & 0.54 & 28.0 & 21.2 & 115.3 & 1.1 \\
\hline MS-3 & 11 & 19 & 13.0 & 0.32 & 30.1 & 11.7 & 123.6 & 1.0 \\
\hline MS-4 & 11 & 27 & 18.0 & 0.47 & 34.7 & 23.3 & 130.9 & 0.3 \\
\hline MS-6 & 11 & 14 & 7.7 & 0.36 & 41.7 & 12.0 & 124.2 & 1.0 \\
\hline OKO-IYAWO & 11 & 11 & 6.7 & 0.30 & 31.9 & 38.3 & 104.0 & 0.7 \\
\hline TME-1 & 11 & 25 & 13.4 & 0.33 & 33.4 & 27.5 & 101.5 & 1.2 \\
\hline TME-2 & 11 & 19 & 20.6 & 0.38 & 30.0 & 25.5 & 120.2 & 1.0 \\
\hline TME-3 & 11 & 20 & 12.9 & 0.42 & 32.5 & 9.4 & 120.7 & 0.0 \\
\hline
\end{tabular}


In terms of fresh root yield, the following accessions were superior to the standard genotypes: $88 / 02555,91 / 02312,92 / 02325$ and Alice Local. In terms of harvest index, accessions 91/00453, 91/02324, 92/02325, 92/0509, 92/0520 and Alice Local were superior to the standard genotypes. The following accessions were superior in terms of dry matter: 2nd Agric, 90/00099, 90/01204, 91/00451, 91/00457, 91/01411, 91/02214, 91/02226, 91/02316, 91/02317, 91/02324, 92/02325, 92/0033, 92/0067, 92/0099, 92/0397, 92/0455, 92/0496, 92/0509, 92/0520, 92/0536, CB5-10 (80411), Isu, Lapai-1, M85/00665, MS-6 and Tokunbo.

Cyanide potential levels of all the accessions were within acceptable limits; however, accessions 90/01718, 91/00420 and 92/0755 had levels below $5.0 \mathrm{mg} \mathrm{HCN} / \mathrm{kg}$, making them superior to the standard genotypes. In terms of mean plant height, accessions 88/02555, 90/00099, 91/00397, 91/00417, 91/00795, 91/01964, 91/01986, 91/02214, 91/02226, 91/02233 91/02312 92/0033, 92/0057, 92/0174, 92/0427, 92/0455, 92/0602, 92/0616, 92/0681, 92/0723 and Lapai-1 were superior. In terms of level of branching, the following accessions were superior: 91/00417, 91/00451, 91/00457, 91/01921, 91/02214, 92/0427, 92/0496, 92/0602 and 92/0723. The unreplicated entries did not differ significantly among blocks.

Among the identified superior clones, accessions 92/0067 and MS-6 scored the highest percent dry matter of 41.0 and 41.7, respectively. The highest root numbers of 51,55 and 56 were scored by accession 92/0681, 92/02325 and 92/0455, respectively. Alice Local and 88/02555 scored over $32.0 \mathrm{t} / \mathrm{ha}$ for fresh root yield. These accessions together with those CNP values below 5.0 $\mathrm{mg} \mathrm{HCN} / \mathrm{kg}$, highest mean plant height and level of branching could be selected and put into crossing block to combine these traits into one genotype; this process can be facilitated by the fact that cassava is an open pollinated crop.

The results (Table 5) show significant correlation between fresh yield and harvest index. Level of branching was correlated positively with mean plant height and cyanide potential but negatively with harvest index. The negative correlations would call for caution in the comparison and selection approach. The superior clones identified in relation to the standard genotypes indicate that augmented designs can be a useful tool in the selection of superior clones for desirable traits in field experiments with cassava and, possibly, other root crops.

TABLE 5

Pearson Correlations among the five agronomic characters. (Values below are the p-values)

$\begin{array}{lllll}F Y L D & H I & D M & C N P & M P H T\end{array}$

HI $\quad 0.777$

0.000

$\mathrm{DM} \quad-0.184 \quad-0.108$

$0.070 \quad 0.291$

$\begin{array}{llll}\text { CNP } & -0.116 & -0.114 & -0.029\end{array}$

$\begin{array}{lll}0.256 & 0.262 & 0.777\end{array}$

$\begin{array}{llrll}\text { MPHT } & -0.017 & -0.324 & 0.078 & 0.117\end{array}$

$\begin{array}{llllll}\text { LOBR } & -0.077 & -0.197 & -0.050 & 0.207 & 0.224\end{array}$




\section{Acknowledgment}

The authors are grateful to Dr R. U. Okechukwu for assisting in the computer data analysis.

\section{References}

Federer W. T. (1961). Augmented designs with one way elimination of heterogeneity. Biometrics 17: 447-473.

Marmey P., Beeching J. R., Hamon S. and Charrier A. (1994). Evaluation of cassava (Manihot esculenta Crantz) germplasm collection using RAPD markers. Euphytica 74: 203-209.

Roa A. C., Maya, M. M., Duque M. M., Tohme J., Allen A. C. and Bonierbale M. W. (1997). AFLP analysis of relationships among cassava and other Manihot species. Theor. appl. Genet. 95: 741-750.

Spehar C. R. (1994). Field screening of soya bean (Glycine max (L.) Merril) germplasm for aluminium tolerance by use of augmented design. Euphytica 76: 203-213.

Scott R. A. and Milliken G. A. (1993). A SAS program for analyzing augmented randomized complete block designs. Crop Sci. 33: 865-867.

Wolfinger R. D., Federer W. T. and Cordero-Brana O. (1997). Recovering information in augmented designs using SAS PRO GLM and PROC MIXED. Agron. J. 89: 856-859. 